\title{
Análisis musical de La guerra de las galaxias: el nuevo sinfonismo y el uso del leitmotiv
}

\section{Musical analysis of Star Wars: the new symphonic music and use of leitmotif}

\author{
Dr. Jorge Gallardo. Universidad Camilo José Cela
}

Dra. Eva Margarita Gallardo. Universidad de Málaga

Recibido: 2-XII-2012 - Aceptado: 24-VII-2013

Resumen:

Este artículo analiza la utilización de la música del compositor John Williams en la película La guerra de las galaxias (1977) de George Lucas. Contextualiza y relaciona el análisis con lo que supuso el film para impulsar el uso del nuevo sinfonismo en el cine de la mano de Williams a finales de los 70. Los autores aprovechan los conocimientos audiovisuales y musicales de sus respectivas áreas de conocimiento para analizar el uso de la música en la película de George Lucas en los siguientes puntos: los leitmotiv principales, la sincronización, el tiempo y la clasificación de la música ausente y presente utilizada en el film. El estudio concluye que la presencia musical y el uso de los leitmotiv aportan una importante e imprescindible carga narrativa en una obra cinematográfica en la que, desde ese momento, el compositor adquiere un papel importante en la construcción de la narración audiovisual.

Palabras clave:

cine, película, sinfonismo, banda sonora, música, George Lucas, John Williams, La guerra de las galaxias Abstract:

This research analyzes the use of music by composer John Williams in the movie Star Wars (1977) directed by George Lucas. This analysis contextualizes and relates to how Star Wars film impulsed the use of new symphonism in the music contemporary cinema. The authors make a brief review of theoretical and historical birth of the new symphonism by Williams in the late 70's. And they also take the audiovisual and musical knowledge in their respective areas to analyze in detail the use of music in the film by George Lucas: the main leitmotif, synchronization, time and the classification of music on and off. The study concludes that musical presence and the leitmotif uses add an important and essential narrative part to Star Wars film. From this moment, the composer takes an important role in the construction of the audiovisual narrative.

Keywords:

cinema, film, symphonic, soundtrack, music, George Lucas, John Williams, Star Wars 


\section{Introducción}

El nuevo sinfonismo posiciona a la música cinematográfica como sustrato ambiental de la imagen por encima en calidad a la película, pero además equipara la importancia del compositor a la del director. A finales de los años 70 (concretamente en 1977) renace el sinfonismo de la mano del compositor John Williams gracias a la música compuesta para la película La guerra de las galaxias dirigida por Georges Lucas.

Las investigaciones existentes sobre esta película se limitan a hacer referencias históricas y no profundizan, en su mayoría, en un análisis cuantitativo sobre la música utilizada. En este sentido, el artículo aporta un análisis pormenorizado del uso de la música en La guerra de las galaxias de utilidad para los estudiantes e investigadores del área de las Ciencias de la Comunicación.

\subsection{El inicio del neosinfonismo}

Pablo Mérida de San Román (2002) asevera que después de varios años de crisis en el cine norteamericano, este resurge en los años 70 con gran fuerza y coincide, entre otros factores, con la incorporación de bandas sonoras espectaculares. Llega la denominada era del cine-espectáculo que consiguió muy buena recaudación en las salas. Concretamente, La guerra de las galaxias se convirtió en un fenómeno social. Esta película es una claro ejemplo de lo que Hernández y Grandío (2011) denominan como "narrativa crossmedia" donde se crean fenómenos fan en torno a una saga para ahondar en universos narrativos profundos. George Lucas ofreció al público lo que estaba esperando: diversión, espectáculo y evasión.

En este contexto, Olarte (2002: 5) recuerda que la década de los 70 es considerada como el periodo más complicado para la partitura cinematográfica "por la aparición de elementos musicales ajenos a la esencia de la música de cine y que restaban expresividad, como fueron las canciones y músicas discotequeras, que estaban de moda entre la gente joven”. Sin embargo, también añade que Williams "con su gran éxito comercial hizo replantearse la banda sonora en boga". Se pone de moda el estilo de la escuela neosinfónica con John Williams y otro gran compositor: Jerry Goldsmith (Star Trek, 1979; Poltergeist, 1982; etc.). Sin embargo, no olvidemos que el inspirador de John Williams para apostar por el sinfonismo en el cine fue el compositor austriaco de música cinematográfica Max Steiner que, como la máxima representación del sinfonismo clásico, inspiró también a James Horner (Leyendas de pasión, 1994) y Poledouris (La caza del Octubre Rojo, 1990), entre otros. Los años 70 supusieron la consolidación del "nuevo Hollywood" donde "el desarrollo más significativo de empresas de entretenimiento durante estos años [...] se dirige hacia la creación de sinergias y la diversificación de actividades empresariales" (Prado, 2011: 50).

Por tanto, la vuelta al sinfonismo se produce con el compositor John Williams y su partitura para la película La guerra de las galaxias (Williams, 2004). Su composición está hecha para una gran orquesta sinfónica, al modo de los clásicos de los 
años 40. El éxito mundial que tuvo el volver al sinfonismo hizo que despertara de nuevo el interés por la música cinematográfica (Padrol, 2001). Sin embargo, la forma de hacer música en el cine de Williams despierta críticas. Su neosinfonismo es criticado como "sinfonismo industrial” y catalogado despectivamente como el “williallismo"; entendido éste como una "epidemia caracterizada por la elefantiasis orquestal y la carencia de originalidad tanto en la composición como en el concepto de la relación música-imagen” (Colón, Infante del Rosal y Lombardo, 1997: 173).

Según Chion (1997) la música de La guerra de las galaxias fue bastante importante y sirvió de ayuda a compositores posteriores por su papel narrativo a través del uso del leitmotiv vinculado a personajes o situaciones (algo que ya fue utilizado en el romanticismo por Wagner). Marschall (1996: 630) afirma que los leitmotiv cambian en función de la acción, del pensamiento y de los estados de ánimos de los personajes; y que "sirven de base a la tarea sinfónica de la orquesta y constituyen lo que Wagner entendía como melodía infinita". Chion (1997: 259-260) pone en valor una teoría sobre "la relación de la música de John Williams en La guerra de las galaxias con la Tetralogía de Wagner”. Los motivos para realizar esta comparación fueron los siguientes:

- $\quad$ Ambos compositores han elaborado su obra a partir del leitmotiv.

- Wagner y Williams utilizan una orquesta voluminosa y con mucho metal.

- $\quad$ El romanticismo al estilo del siglo XIX y la utilización del cromatismo en ambas obras.

- Williams retoma los sistemas dramatúrgicos utilizados en la Tetralogía, como la puntuación de la acción.

- $\quad$ Utilización de ostinatos rítmicos y melódicos para poder así prolongar el material temático.

Williams utiliza métodos wagnerianos como los llamados corales.

Mientras unos alaban el uso del leitmotiv en la música de cine, otros como Adorno y Eisler (1981: 18) lo critican, diciendo que "fue siempre la más vasta forma de ilustración y la falsilla para la gente sin formación musical”. Citan a Wagner para lamentar que en su música no hay nada más que repeticiones sin apenas modificaciones e insisten en que el leitmotiv no caracteriza sólo a las personas o las emociones (aunque ya lleve implícita esa función) sino que debe "elevar el acontecimiento escénico a la esfera de lo metafísicamente significativo” (Adorno y Eisler, 1981: 19-20).

Sin embargo, para Chion (1997: 220) “el leitmotiv da elasticidad y gran fluidez al transcurso musical”. Por su parte, Alcalde de la Isla (2007: 7-8) afirma que el leitmotiv tiene una idoneidad fílmica por sus cualidades:

Los temas fijos aportan unidad y coherencia al conjunto y se convierten en puntos de anclaje que ahorman el discurso.

Se trata de motivos plásticos, flexibles, formas abiertas susceptibles de tratamientos tonales, tímbricos y rítmicos que permiten componer desde un principio de economía temática (pocos temas). 
- $\quad$ La motivación es extramusical.

- $\quad$ Es repetitivo y, por tanto, unificador y económico.

- Es "indicial”, está ahí como un factor de atmósfera o de sentimiento, de calificación (como el vestuario o el decorado).

La partitura de la película de La guerra de las galaxias fue y es una de las más importantes de la historia del cine ya que volvió a utilizar la banda sonora sinfónica y el leitmotiv wagneriano, creando leitmotiv originales asociados a cada personaje (Marschall, 1996) que desglosaremos en este artículo. La música del cine siempre ha sido un material de apoyo, subsidiaria de la imagen o de la historia contada. Por ello, las soluciones puras nunca han funcionado en la música del cine con la excepción de músicos como Williams que "han sabido resolver el aspecto funcional al margen de las formalidades musicales” (Alcalde de la Isla, 2007: 8). El compositor repite el mismo leitmotiv en las cinco películas posteriores pero en cada una de ellas añade "diferentes temas más o menos memorables que han cobrado independencia propia. Es el padre del espíritu orquestal de los compositores cinematográficos de los años 30” (González, 2006: 75).

Para Chion (1996) la vuelta al sinfonismo está ligada a la aparición del Dolby Stereo, un sistema creado para garantizar en las salas la mejor calidad posible en la proyección y el sonido. Los investigadores García y Sánchez (1997) añaden que la película La guerra de las galaxias fue la primera en utilizar este nuevo sistema que dispone de cuatro pistas.

Como reconocimiento a sus aportaciones a la industria, en 1992 se le otorgó a John Williams el premio Irving G. Thalberg (Mérida de San Román, 2002).

\subsection{El director y el compositor}

El trabajo de George Lucas y John Williams supuso un antes y después en la manera de contar historias en el cine. De ahí la importancia de que conozcamos someramente la trayectoria de los creadores del objeto de estudio.

George Lucas nació el 14 de mayo de 1944 en la localidad californiana de Modesto (Lucena e Indurain, 2002). En California estudió cine y tras realizar varios cortos conoció a Coppola con quien entabló una gran amistad y formó una pequeña compañía llamada American Zoetrope. Fue aquí donde rodó su primer largometraje THX 1138 (que no tuvo gran éxito). Tomaron caminos distintos cuando Coppola se centró en la grabación de El padrino y Lucas formó su propia productora llamada Lucasfilm con la que rodó American Graffiti. El género de ciencia ficción quedó consolidado con Georges Lucas y su exitosa película La guerra de las galaxias. La ciencia ficción se convertiría en espectáculo y diversión. Bookbinder (1996) dice que Georges Lucas en ningún momento se imaginó el exitazo que iba a obtener este film, su única intención era hacer prevalecer el bien sobre el mal y que disfrutasen los niños, pero realmente disfrutaron tanto niños como personas adultas. En un principio quiso hacer un remake de los seriales de Flash Gordon de los años 30, pero se encontró con 
varios problemas, el primero era que los derechos eran excesivamente caros y el segundo, que los propietarios ejercerían un enorme control sobre la producción. Fue por estas causas por las que no se llevó a cabo.

Podríamos suponer que los grandes estudios cinematográficos se rifarían a Lucas cuando éste enseñara el guión, pero desafortunadamente no sucedió así. Lucas mostró un esbozo, de unas catorce páginas, a United Artist y a la Universal, pero ambas demostraron muy poco interés ya que las películas que, hasta ese momento se habían producido de ciencia ficción, no habían tenido mucho éxito o tenían un público muy limitado. La 20th Century-Foxfue la que aceptó finalmente financiar el proyecto de Lucas.

La película se estrenó en mayo de 1977 y recuperó en menos de dos meses los nueve millones de dólares que costó la producción y publicidad. No sólo fue un gran boom en las taquillas, sino también en la industria del comercio con la creación de los juguetes de los personajes de la película, camisetas, tazas, espadas o la venta de la propia banda sonora. Lucas quiso que cada fragmento de la película estuviese desarrollado al milímetro para mantener al espectador en vilo durante todo el film. Su intención fue que la audiencia no apartara la vista de la pantalla ni un solo segundo y, ahí, la música de Williams tuvo gran importancia.

Por otra parte, Carretero et al. (2001: 312) han bautizado a Williams como "la estrella absoluta del neosinfonismo". Nació en New York en el año 1932 en el seno de una familia de músicos. Se formó en Los Ángeles donde recibió clases particulares de Mario Castelnuovo-Tedesco. Su comienzo como compositor fue escribiendo partituras para diversas series. Fueron estas partituras tan bien escritas las que le abrieron las puertas para entrar en la industria cinematográfica. Según Colón (1993) en los años cincuenta se incorporó al departamento musical de la Fox como arreglista y orquestador colaborando con Hermann, Newman y Waxman. Será reconocido como compositor en los años 60 con títulos como Penélope. Pero su primera gran reputación como arreglista y orquestador en comedias musicales fue con Adiós Mr. Chips (1969) y El violinista en el tejado (1971). Sin embargo, no sería considerado como un gran compositor hasta la década de los 70, cuando trabajó con Steven Spielberg (en la película Tiburón del año 1975) y, dos años después, con Georges Lucas.

Pero Carretero et al. (2001) recuerdan que Williams además de componer para películas también compuso obras para salas de concierto de las que podemos destacar dos sinfonías: un concierto para flauta y un concierto para fagot. En 1980 fue nombrado director de la Boston Pops Orchestra. El trabajo realizado por Lucas y Williams en la película La guerra de las galaxias cosechó cinco Oscar (mejor montaje, mejor vestuario, mejores efectos especiales, mejor dirección artística y mejor sonido).

\section{Objetivos y metodología}

El principal objetivo de este artículo es demostrar a través de un análisis cuantitativo y cualitativo la importancia del uso de la música para la carga narrativa en la película que supuso el renacimiento del sinfonismo: La guerra de las galaxias. 
Añadiremos a los análisis históricos observados en el marco teórico, un análisis pormenorizado que demostrará cómo la banda sonora adquiere personalidad y una importancia nunca vista hasta el momento en la narración audiovisual.

Para ello utilizaremos una metodología principalmente cuantitativa basada en la observación de la obra original La guerra de las galaxias (1977). Para realizar este análisis se ha dividido la película en 49 escenas de las que se ha anotado el uso de la música (presentelausente), el leitmotiv vinculado a los personajes, el contenido de cada escena y el minutaje. Esta clasificación es la aconsejada por algunos investigadores a la hora de analizar la música en obras audiovisuales (López Hernández, 2003; Montoya, 2010). Concretamente, se han cronometrado cada una de las escenas de la película en DVD ${ }^{1}$ (Lucas, 2004 y Williams, 2004) para: relacionar el contenido con la música, medir los minutos de música presentey ausente y valorar el tipo de música utilizada.

Para la realización de las tablas y la recopilación de los datos tuvimos en cuenta la hoja de análisis secuencial de contenido fílmico propuesta por López Hernández (2003). En lo que respecta a la manipulación de los datos cuantitativos hemos utilizado el software Excel y hemos vinculado el minutaje de cada escena con una descripción detallada de la utilización de la música como observaremos en los Cuadros 1, 2 y 4.

En el ámbito cualitativo, la metodología está relacionada con la conceptualización musical de Chion (1996, 1997) y de Cueto (1996). Si utilizamos el término banda sonora en un sentido amplio nos referimos a todo el soporte sonoro que acompaña a las imágenes de un film; es decir, a los diálogos, a los efectos del sonido y a la música. En un sentido más estricto (que es el empleado en este artículo) el término se limita a la música del film, es decir, a las partituras musicales. Pero para comprender el uso de la música y la clasificación de La guerra de las galaxias debemos distinguir los tres tipos de músicas que detalla Cueto (1996): a) la música diegética, b) la música extradiegética y c) el cine musical.

De esta manera, para cumplir el objetivo de este artículo analizaremos la importancia de la banda sonora de la película a través de una visión cuantitativa y cualitativa basada en la recopilación de datos relacionados con:

- $\quad$ Los leitmotiv principales (metodología cuantitativa, captación de datos a partir de las 49 escenas).

- La sincronización y el tiempo del uso de la música (metodología cuantitativa, captación y cronometraje de tiempos a partir de las 49 escenas).

- La clasificación de la música utilizada (metodología cualitativa basada en la observación a partir de la conceptualización de teóricos como Chion y Cueto).

1 Se trata de una edición "masterizada digitalmente para una calidad superior de imagen y sonido" según indica la carátula de la película que mantiene los parámetros narrativos y audiovisuales de la primera edición de 1977. Los investigadores utilizaron esta edición por su facilidad de manejo en DVD. Sin embargo, se realizó un visionado comparativo de la versión de 1977 (en VHS) para comprobar que no existían diferencias notables en la banda sonora utilizada en el film. 


\section{Resultados y discusión de la investigación}

John Williams comprendió al ver la película sin audio que el estilo de música que necesitaba era un estilo sonoro cercano al tradicional sin experimentaciones musicales como las de otros compositores. Por ello, la música que compuso fue tonal y orquestal. Para poder interpretarse la partitura se necesitaba una plantilla orquestal formada por 116 músicos (de ahí el retorno al estilo sinfónico). Los instrumentos utilizados en la Suite Star Wars (música que suena al principio de la película cuando se narra la historia), es la siguiente: flautas, picolo, oboe, clarinete, clarinete bajo, trompas, trompetas, trombones, trombón bajo, tuba, percusión, arpa, piano y cuerdas (violín, viola, violonchelo y contrabajo). Nada que ver con los otros compositores que, por esta época, hacían uso de la música electrónica (especialmente en las películas de ciencia ficción). Los primeros siete minutos de la película son una clara declaración de intenciones como vemos en el Cuadro 1: la música es la protagonista desde el primer minuto².

Todas estas tablas detalladas se encuentran a disposición de cualquier investigador que lo solicite ya que no pueden añadirse al artículo debido a su gran extensión (17 páginas). 
Cuadro 1. Análisis de los primeros siete minutos de La guerra de las galaxias

\begin{tabular}{|c|c|c|c|c|}
\hline ESCENA & MÚSICA & $\begin{array}{l}\text { LEITMOTIVI } \\
\text { Personajes }\end{array}$ & DESARROLLO DEL CONTENIDO & $\begin{array}{l}\text { MINU- } \\
\text { TAJE }\end{array}$ \\
\hline $\begin{array}{l}\text { Una nueva } \\
\text { esperanza }\end{array}$ & $\begin{array}{l}\text { Main Tittle (cré- } \\
\text { ditos de } \\
\text { introducción) }\end{array}$ & LUKE & $\begin{array}{l}\text { La música comienza junto con los créditos de la película e } \\
\text { interviene toda la orquesta. La música nos presenta el fa- } \\
\text { moso tema de La guerra de las galaxias }\end{array}$ & 0’28" \\
\hline \multirow{2}{*}{$\begin{array}{l}\text { Partida im- } \\
\text { perial de } \\
\text { abordaje }\end{array}$} & $\begin{array}{l}\text { Rebel Blockade } \\
\text { Runner }\end{array}$ & \multirow{2}{*}{ DARTH VADER } & $\begin{array}{l}\text { La nave donde está la princesa Leia está siendo atacada } \\
\text { por el ejército del Imperio. La música es de tempo allegro, } \\
\text { muy marcial con la intervención de instrumentos de per- } \\
\text { cusión (timbales). }\end{array}$ & $2^{\prime}$ \\
\hline & \multirow{4}{*}{ Imperial Attack } & & $\begin{array}{l}\text { Cuando asalta la nave el ejército del Imperio, la música } \\
\text { que suena es entrecortada y disonante intentando aseme- } \\
\text { jarse con los disparos que se están realizando, para más } \\
\text { tarde volver a tocar el leitmotiv de Darth Vader. }\end{array}$ & 3’30" \\
\hline \multirow{3}{*}{$\begin{array}{l}\text { La misión } \\
\text { de Artoo }\end{array}$} & & $\begin{array}{l}\text { PRINCESA LEIA } \\
\text { / DARTH VADER }\end{array}$ & $\begin{array}{l}\text { Cuando la princesa introduce la información al androide } \\
\text { R2-D2. Es la primera vez que nos presentan el motivo me- } \\
\text { lódico de Leia que será lírico, y que se verá interrumpido } \\
\text { por el esquema rítmico del leitmotiv de Darth Vader (aun- } \\
\text { que no llega a sonar el leitmotiv melódicamente, 5'20"). }\end{array}$ & $41^{\prime \prime}$ \\
\hline & & LEIA & $\begin{array}{l}\text { El ejército busca a Leia hasta que la encuentran y la cogen } \\
\text { prisionera. }\end{array}$ & 6’02” \\
\hline & & Androides & $\begin{array}{l}\text { Los androides C3-PO y R2-D2 necesitan poner a salvo la } \\
\text { información que le ha dado Leia y huyen de la nave via- } \\
\text { jando por el espacio. La música que escuchamos tiene } \\
\text { progresiones descendentes aumentando así la tensión } \\
\text { antes de iniciar el viaje por el espacio, sonarán las cuerdas } \\
\text { con una melodía más lírica cuando estén fuera de peligro. }\end{array}$ & $6^{\prime} 40^{\prime \prime}$ \\
\hline
\end{tabular}

Fuente: Elaboración propia 
Con respecto a estos primeros minutos, González (2006: 76) afirma que "el tema principal de la película, universalmente conocido, comienza con una fanfarria de metales, a la que se unirán percusión y cuerdas, que inunda la pantalla al mismo tiempo que aparece el título de la película".

\subsection{La función de la música en La guerra de las galaxias}

Cueto (1996: 21-33) recuerda las palabras del productor Jack Warner cuando asevera que el cine es fantasía y que, como fantasía, necesita de la música. El director y arreglista Mathieson asegura que "la música no necesita para nada del cine, pero el cine sí necesita a la música". La función de la música en el cine en sus inicios consistía en tapar el molesto ruido del proyector, pero muy pronto se crearían composiciones originales para el film y se empezaría a desarrollar un lenguaje musical según las necesidades del medio. Pero para que la interacción entre la música y el cine se produzca, es necesario un "contrapunto". Entendido ese "contrapunto" como dos líneas expresivas que desarrollan su propia línea para enriquecer el resultado final. A continuación planteamos las funciones de la música de Cueto (1996) y cuáles son las que destacan en La guerra de las galaxias:

- $\quad$ Dar el verdadero significado de un film.

- Crear el tono y atmósfera de un film.

- $\quad$ Acelerar o retardar la acción.

- $\quad$ Recrear una época o un ambiente.

- $\quad$ Anticipar o indicar cuál es el tono o significado de una escena.

- Intensificar el sentido de una escena o llamar la atención sobre su importancia dramática. Desde el momento en que el director, el montador y el músico deciden qué escenas llevarán música están dando ya el primer paso para componer y se le conoce con el nombre spotting.

- Dar cohesión a diferentes escenas. La música es el mejor elemento para suavizar el paso de una escena a otra cuando se desarrolla en distinto tiempo y/o espacio.

- $\quad$ Recuerdo de elementos anteriores. En este apartado nos estamos refiriendo al leitmotiv. Esta técnica es la que utiliza John Williams en su composición para la película La guerra de las galaxias.

- Dar credibilidad a una película. El cine fantástico y el de ciencia ficción precisa de la música, ya que este tipo de películas están desligadas a la realidad y la música sirve como un vínculo entre lo fantástico y el espectador. Esto ocurre en La guerra de las galaxias. 
- Clarificar y/o mostrar la psicología o el carácter de un personaje. Los leitmotiv también aportan esta información al espectador en el film de Lucas.

- $\quad$ Subvertir la imagen o dar un matiz irónico.

Y es que "para evitar que la música sea un mero ornamento y llegue a ser repetitiva, la buena música de cine debe ofrecer algo que no lo pueda aportar nada más” (Cueto, 1996: 33). ¿Sucede esto con la música de La guerra de las galaxias? Vamos a profundizar con los resultados de la investigación.

\subsection{El uso de los leitmotiv}

En la película La guerra de las galaxias destaca el uso de cuatro leitmotiv principales. Vamos a analizarlos y describirlos:

- Leitmotiv de Luke Skywalker. Cuyo tema musical es de carácter heróico. Su leitmotiv es el más conocido, es el tema de la famosa Guerra de las Galaxias (aparece al principio junto con los créditos del film).

- Leitmotiv de la princesa Leia. Su tema es lírico y muy melódico, los instrumentos que intervienen en su melodía son los violines, el arpa y no hay percusión.

- $\quad$ Leitmotiv de Obi Wan Kenobi (Ben). Es el tema de la fuerza cuya melodía es serena y más trascendental.

- $\quad$ Leitmotiv de Lord Darth Vader. La música es de tempo allegro, siempre al estilo de una marcha. La percusión (con predominio de los timbales) se impondrá al carácter lírico que tienen los tres anteriores leitmotiv.

En el Cuadro 2 vemos que el número de apariciones del leitmotiv de Luke (protagonista principal) frente al de Darth Vader (el enemigo del protagonista) son similares. Los otros dos personajes secundarios (Ben y Leia) tienen menos apariciones.

Cuadro 2. El uso de los leitmotiv principales clasificados por escenas

\begin{tabular}{|c|c|c|c|}
\hline LUKE & DARTH VADER & BEN & LEIA \\
\hline $\begin{array}{l}\text { - Al comienzo de la película } \\
\left(0^{\prime} 28^{\prime \prime}\right) \text {. }\end{array}$ & $\begin{array}{l}\text {-Partida Imperial de abor- } \\
\text { daje (2'). }\end{array}$ & $\begin{array}{l}\text { - Puesta de sol binaria } \\
\left(24^{\prime} 30^{\prime \prime}\right) .\end{array}$ & · La misión de Artoo (4’41”). \\
\hline $\begin{array}{l}\text { - Androides en venta } \\
\left(16^{\prime} 30^{\prime \prime}\right) .\end{array}$ & $\begin{array}{l}\text { - Partida Imperial de abor- } \\
\text { daje (3’30”). }\end{array}$ & - Vuelta al garaje (25’44”). & · La misión de Artoo (6’02”). \\
\hline $\begin{array}{l}\text { - Cena familiar de los Lars } \\
\text { (24’09”). }\end{array}$ & $\begin{array}{l}\text { - La espada láser de tu padre } \\
\left(33^{\prime} 10^{\prime}\right) .\end{array}$ & $\begin{array}{l}\text { - Encuentro con el viejo Ben } \\
\left(28^{\prime} 25^{\prime}\right) .\end{array}$ & · En el garaje (20’17”). \\
\hline - Vuelta al garaje (25’28”). & $\begin{array}{l}\text { - Una granja incendiada } \\
\left(39^{\prime} 15^{\prime \prime}\right) \text {. }\end{array}$ & $\begin{array}{l}\text { - Una granja incendiada } \\
\left(38^{\prime} 16^{\prime \prime}\right) .\end{array}$ & - El mensaje de Leia (33’28”). \\
\hline
\end{tabular}




\begin{tabular}{|c|c|c|c|}
\hline LUKE & DARTH VADER & BEN & LEIA \\
\hline $\begin{array}{l}\text { - El destino de la Estrella de } \\
\text { la Muerte (50,07”). }\end{array}$ & $\begin{array}{l}\text { - El Halcón Milenario } \\
\text { (52'49”). }\end{array}$ & $\begin{array}{l}\text { - La decisión de Luke } \\
\text { (39'15”). }\end{array}$ & $\begin{array}{l}\text { - Una granja incendiada } \\
\text { (39'15”). }\end{array}$ \\
\hline · El Halcón Milenario (52’). & $\begin{array}{l}\text {. "Eso no es una luna...” } \\
\text { (1:01'50"). }\end{array}$ & $\begin{array}{l}\text { - Puerto espacial de Mos Eis- } \\
\text { ley (42'12"). }\end{array}$ & $\begin{array}{l}\text { - El rescate de la princesa } \\
\left(1: 12{ }^{\prime} 54^{\prime \prime}\right) .\end{array}$ \\
\hline $\begin{array}{l}\text { - Planificando la huida } \\
\left(1: 05^{\prime} 36^{\prime \prime}\right) .\end{array}$ & $\begin{array}{l}\text { - Compartimento secreto } \\
\text { (1:04'58”). }\end{array}$ & $\begin{array}{l}\text { · El Halcón Milenario } \\
\text { (53’11”). }\end{array}$ & - Vuelta a la nave (1:25’32"). \\
\hline $\begin{array}{l}\cdot \text { Wookiee prisionero } \\
\left(1: 10^{\prime} 54 "\right) .\end{array}$ & $\begin{array}{l}\text { - El rescate de la princesa } \\
\text { (1:12'47”). }\end{array}$ & $\begin{array}{l}\text { - Compartimento secreto } \\
\left(1: 04^{\prime} 58 ”\right) .\end{array}$ & · Títulos finales (1:55’20”). \\
\hline $\begin{array}{l}\text { - El rescate de la princesa } \\
(1: 11 \text { '11”). }\end{array}$ & - En el recolector (1:14’35"). & $\begin{array}{l}\text { - Obi-Wan contra Vader } \\
\left(1: 28^{\prime} 35^{\prime \prime}\right) .\end{array}$ & \\
\hline $\begin{array}{l}\text { - El rescate de la princesa } \\
\left(1: 13^{\prime} 06^{\prime \prime}\right) .\end{array}$ & $\begin{array}{l}\text { - Las paredes se cierran } \\
\text { (1:19'03”). }\end{array}$ & $\begin{array}{l}\text { - Obi-Wan contra Vader } \\
\left(1: 29^{\prime} 40^{\prime \prime}\right) .\end{array}$ & \\
\hline - Vuelta a la nave (1:23'29"). & · Vuelta a la nave (1:24'03”). & $\begin{array}{l}\text { - El asalto a la Estrella de la } \\
\text { Muerte (1:40’45”). }\end{array}$ & \\
\hline - Vuelta a la nave (1'24'48'). & Vuelta a la nave (1:25’40"). & $\begin{array}{l}\text { - El asalto a la Estrella de la } \\
\text { Muerte (1:42'37”). }\end{array}$ & \\
\hline - Vuelta a la nave (1:25'54"). & $\begin{array}{l}\text { - Obi-Wan contra Vader } \\
\left(1: 29^{\prime} 10^{\prime \prime}\right) .\end{array}$ & - Usa la fuerza (1:50’56”). & \\
\hline - Usa la fuerza (1:50'37"). & $\begin{array}{l}\text { - Ataques de cazas Tie Figh- } \\
\text { ter (1:30'44"). }\end{array}$ & $\begin{array}{l}\text { - Ceremonia de entrega de } \\
\text { medallas (1:53'39”). }\end{array}$ & \\
\hline - Usa la fuerza (1:57'16”). & $\begin{array}{l}\text { - El asalto a la Estrella de la } \\
\text { Muerte (1:42’37”). }\end{array}$ & & \\
\hline $\begin{array}{l}\text { Ceremonia de entrega de } \\
\text { medallas (1:53'39"). }\end{array}$ & - Trincheras (1:49'22"). & & \\
\hline \multirow[t]{2}{*}{ - Títulos finales (1:55’20”). } & . Usa la fuerza (1:52’48”). & & \\
\hline & - Títulos finales (1:55’20’). & & \\
\hline
\end{tabular}

Fuente: Elaboración propia

Sin embargo, los androides C3-PO y R2-D2 no tienen un leitmotiv definido (al menos, en esta primera parte de la trilogía que más tarde se convertirá en el capítulo IV de la saga). Cada vez que salen en escena suena una música un tanto minimalista pero siempre interpretada por la orquesta. Por tanto, observamos que los instrumentos que intervienen en la 
melodía de cada leitmotiv están asociados con el carácter de los personajes principales y secundarios: por ejemplo, Jabba, una criatura corpulenta con unos andares lentos, es un personaje asociado con el instrumento de la tuba (Jabba es corpulento y de pasos lentos y la tuba es de grandes dimensiones y suele tener notas de larga duración).

Los leitmotiv que aparecen en esta película varían de tonalidad musical (mayor o menor, dependiendo de la situación de ese momento en la que se desarrolla la acción o según el estado de ánimo del personaje). Incluso se desarrollan a medida que transcurre la película. John Williams lleva a cabo estos leitmotiv con una gran exquisitez y asocia incluso cada instrumento (ya no sólo la melodía) a un personaje determinado para potenciar así la diferencia entre ellos. Podemos citar, por ejemplo, el tema del Imperio (leitmotiv de Darth Vader) y el de la princesa Leia (véase el Cuadro 2). El primero es mucho más rítmico con un tempo allegro, emulando una marcha militar con instrumentos de vientos, metal y predominio de la percusión (concretamente los timbales); mientras que el segundo (el de la princesa Leia), es un tema lírico con la intervención de pocos instrumentos, nada de metales, sino todo lo contrario (instrumentos de cuerdas y el arpa con tempo andante).

También observamos que Williams conjuga muchas veces con gran éxito dos leitmotiv a la vez, como por ejemplo cuando persiguen los cazas imperiales a la nave de Luke. En esta escena escuchamos el leitmotiv de Ben (el de la fuerza) y el de Darth Vader. Por otro lado, en el Cuadro 3 observamos en la escena "Uso de la fuerza" una manera magistral en cuanto a mezclas de dos leitmotiv: el de Luke y el de Darth Vader.

Cuadro 3. La mezcla del leitmotiv en la escena "Usa la fuerza"

\begin{tabular}{|l|l|l|l|l|}
\hline ESCENA & MÚSICA & $\begin{array}{l}\text { LEITMOTIVI } \\
\text { Personajes }\end{array}$ & DESARROLLO DEL CONTENIDO & MINUTAJE \\
\hline $\begin{array}{l}\text { Usa la } \\
\text { fuerza }\end{array}$ & $\begin{array}{l}\text { The battle of } \\
\text { Yavin: } \text { use the } \\
\text { force }\end{array}$ & BEN & $\begin{array}{l}\text { Mientras Luke se va acercando al objetivo escucha la voz de } \\
\text { Ben diciéndole que la fuerza le acompañe (sonido over: acus- } \\
\text { mático extradiegético). La música cambia totalmente de } \\
\text { carácter, es más lírico y transmite seguridad y tranquilidad } \\
\text { en el espectador. }\end{array}$ & $1: 50$ '56” \\
\hline
\end{tabular}




\begin{tabular}{|c|c|c|c|c|}
\hline ESCENA & MÚSICA & $\begin{array}{l}\text { LEITMOTIVI } \\
\text { Personajes }\end{array}$ & DESARROLLO DEL CONTENIDO & MINUTAJE \\
\hline \multirow[t]{2}{*}{$\begin{array}{l}\text { Usa la } \\
\text { fuerza }\end{array}$} & $\begin{array}{l}\text { The battle of } \\
\text { Yavin: use the } \\
\text { force }\end{array}$ & $\begin{array}{l}\text { LUKE/DARTH } \\
\text { VADER }\end{array}$ & $\begin{array}{l}\text { Esta vez el leitmotiv de Luke tiene una particularidad que es } \\
\text { la siguiente. La melodía la tienen las trompetas y las cuerdas } \\
\text { que hacen la función de acompañamiento, pero aparece } \\
\text { también la percusión con un esquema rítmico característico } \\
\text { en el leitmotiv de Darth Vader. Nos vamos a encontrar con } \\
\text { una mezcla de los dos leitmotiv, es decir, la melodía brillante } \\
\text { (leitmotiv de Luke) intenta ser apagada por la célula rítmica } \\
\text { de los timbales (leitmotiv de Darth Vader). El leitmotiv que } \\
\text { predomina es el de Luke (el bien) sobre el de Darth Vader (el } \\
\text { mal). Cuando vuelve a sonar el leitmotiv de Luke lo hará en } \\
\text { otra tonalidad, esta vez en modo menor y con una gran pre- } \\
\text { sencia de los timbales, pues Darth Vader está muy cerca de } \\
\text { nuestro amigo Luke. Cuando Darth Vader tiene en el punto } \\
\text { de mira a Luke aparecerá Han, con su nave, derribando a los } \\
\text { cazas del Imperio dejando el camino libre para que Luke } \\
\text { pueda cumplir con su objetivo. Debemos mencionar otra } \\
\text { gran sincronización de la música con respecto a la imagen, } \\
\text { este momento es cuando Luke envía el misil a la Estrella de la } \\
\text { Muerte y se produce la explosión. }\end{array}$ & $1: 57^{\prime} 16^{\prime \prime}$ \\
\hline & & $\begin{array}{l}\text { DARTH } \\
\text { VADER }\end{array}$ & $\begin{array}{l}\text { Debida a la explosión de la Estrella de la Muerte, Darth Vader } \\
\text { ha sido enviado al espacio. Es el único que se ha salvado. }\end{array}$ & 1:52'48” \\
\hline
\end{tabular}

Fuente: Elaboración propia

De esta manera, la música contextualiza y aporta rasgos característicos a los personajes relacionados con su personalidad e, incluso, con su apariencia física. Es decir, la música se convierte en el hilo conductor de la película y en una parte clave para la comprensión del film. Pero esta carga narrativa de la música se hace más importante gracias a la sincronización y el tiempo de uso de la música. 


\subsection{La sincronización y el tiempo del uso de la música}

Al analizar al segundo la película queda perfectamente reflejado con qué gran maestría se ha realizado la conexión de la película y de la música, ya que van totalmente ligadas (la película necesita de la música como un medio de expresión). Toda la música para este film es original, aunque en un principio Lucas le propuso a Williams que en alguna parte utilizara música existente de otros compositores (como ocurrió con la película 2001: Odisea en el espacio) a lo que Williams se negó.

Existe una gran sincronización (tocando casi la perfección) de la música con la escena que se produce en cada momento. Podemos citar algunas escenas: "estallido del planeta" con gran subida de intensidad de la orquesta (véase el Cuadro 3), cuando los tíos de Luke están muertos suena un acorde final, cuando están ocultos en el Halcón Milenario y abren la trampilla y empieza a sonar la música. En el Cuadro 4 describimos uno de los ejemplos de sincronización musical en la escena "En el recolector" cuando en la caída de Han Solo en el vertedero se produce un acorde final que da paso al silencio.

Cuadro 4. Ejemplo de sincronización musical en la escena "En el recolector"

\begin{tabular}{|l|l|l|l|l|}
\hline ESCENA & MÚSICA & $\begin{array}{l}\text { LEITMOTIVI } \\
\text { Personajes }\end{array}$ & DESARROLLO DEL CONTENIDO & MINUTAJE \\
\hline En el re- & Shootout in \\
colector & the cell bay & DARTH & $\begin{array}{l}\text { Elército del imperio han encontrado a Chewbacca y a Han Solo } \\
\text { yuyen hasta encontrar a Luke y Leia. No tienen escapatoria, } \\
\text { están acorralados. El tema suena forte y al principio lo tocan los } \\
\text { clarinetes, oboes y flautas y después lo repiten (en forma de eco) } \\
\text { las trompas. En este momento nuestros amigos están en peligro, } \\
\text { no hace más que sonar el leitmotiv de Darth Vader con sus varia- } \\
\text { ciones, la música es de tempo allegro y estridente, con } \\
\text { progresiones. Sólo se ve la intención del leitmotiv de la Fuerza } \\
\text { (Ben) cuando Leia busca una salida por los recolectores. Es una } \\
\text { mera intención porque suena una célula de cuatro notas. Esto lo } \\
\text { podemos observar en 1:15'14". } \\
\text { Cuando huyen todos por el boquete que ha abierto Leia, que con- } \\
\text { duce al compactador de la basura, la música tiene una } \\
\text { sincronización con la imagen cuando Han Solo (que es el último } \\
\text { en saltar) cae en la basura, con lo cual se produce un acorde final } \\
\text { dando paso al silencio (1:15'56”). }\end{array}$ & $1: 14$ '35" \\
\hline
\end{tabular}

Fuente: Elaboración propia 
Por otro lado, para demostrar la importancia que tiene la banda sonora en esta película hemos cuantificado el minutaje en el que hay música en el film frente a la música ausente. La ausencia de música en determinadas escenas es tan importante como la misma música pues, en ese momento, el diálogo no necesita de ésta como medio de expresión o como apoyo para reafirmar la escena que está sucediendo. A continuación mostramos en el Cuadro 5 los minutajes de música ausente y presente.

Cuadro 5. Minutaje de música presente y ausente en La guerra de las galaxias

\begin{tabular}{|c|c|c|c|}
\hline \multicolumn{2}{|c|}{ MÚSICA PRESENTE } & \multicolumn{2}{|c|}{ MÚSICA AUSENTE } \\
\hline 0'28"'-8'45" & 8'17" & 8'45"'-10'03" & 2'01" \\
\hline $10^{\prime} 03^{\prime \prime}-10^{\prime} 54^{\prime \prime}$ & $0,51 ”$ & $10^{\prime} 54^{\prime \prime}-12^{\prime}$ & 1'46" \\
\hline $12^{\prime}-17^{\prime \prime}$ & $5^{\prime}$ & $17^{\prime}-18^{\prime} 28^{\prime \prime}$ & 1'28”' \\
\hline $18^{\prime} 28^{\prime \prime}-18^{\prime} 55^{\prime \prime}$ & 0'27" & 18'55"-20'17" & 2’02” \\
\hline $20^{\prime} 17^{\prime \prime}-22^{\prime} 05^{\prime \prime}$ & 2'28" & 22'05"-20'17" & 2’04" \\
\hline $24^{\prime} 09^{\prime \prime}-26^{\prime} 20^{\prime \prime}$ & 2’11" & 26'20"-26’39”' & 0’19”' \\
\hline $26^{\prime} 39^{\prime \prime}-27^{\prime} 08^{\prime \prime}$ & 1'09" & 27'08”-27'27" & 0'12" \\
\hline $27^{\prime} 27^{\prime \prime}-29^{\prime} 25^{\prime \prime}$ & 2’38" & 29'25"-29'49”' & 0’24" \\
\hline 29'49'-31'20" & 2’11” & 31'20"-33'10" & 2’30" \\
\hline $33^{\prime} 10^{\prime \prime}-34^{\prime} 27^{\prime \prime}$ & 1'17” & $34^{\prime} 27-34^{\prime} 44^{\prime \prime}$ & 0’17”' \\
\hline $34^{\prime} 44^{\prime \prime}-35^{\prime} 32^{\prime \prime}$ & 1'28” & $35^{\prime} 22^{\prime \prime}-37^{\prime} 30 "$ & 2’08” \\
\hline $37^{\prime} 30^{\prime \prime}-42^{\prime} 20^{\prime \prime}$ & 5’30" & 42'20"-43’02” & 1'22" \\
\hline 43’02”-45’03" & 3’01" & 45’03"-45'20" & 0’17" \\
\hline $45^{\prime} 20^{\prime \prime}-45^{\prime} 38^{\prime \prime}$ & 0'18" & 45’38”-45’45” & 0’07" \\
\hline $45^{\prime} 45^{\prime \prime}-47^{\prime} 50^{\prime \prime}$ & 2’05” & $47^{\prime} 50 "-47^{\prime} 55^{\prime \prime}$ & 0’05” \\
\hline $47^{\prime} 55^{\prime \prime}-49^{\prime} 09^{\prime \prime}$ & 1’54" & 49'09"-49'36” & 0'27” \\
\hline 49'36"-52'27" & 3’31” & $52^{\prime} 27^{\prime \prime}-52^{\prime} 49^{\prime \prime}$ & 0'22” \\
\hline $52^{\prime} 49^{\prime \prime}-54^{\prime} 58^{\prime \prime}$ & 2’09” & 54’58”-55’49”' & 1’31” \\
\hline $55^{\prime} 49^{\prime \prime}-56^{\prime} 45^{\prime \prime}$ & 1’36” & $56^{\prime} 45^{\prime \prime}-1: 01^{\prime} 50 "$ & 5’05” \\
\hline 1:01'50"-1:03'25” & 2’15" & 1:03’25”-1:04'30" & 1’05" \\
\hline 1:04'30"-1:06'12” & 2'22” & 1:06'12"-1:10’54" & 4'42” \\
\hline
\end{tabular}




\begin{tabular}{|c|c|c|c|}
\hline \multicolumn{2}{|c|}{ MÚSICA PRESENTE } & \multicolumn{2}{|c|}{ MÚSICA AUSENTE } \\
\hline 1:10'54"-1:09'18" & 1'36" & 1:09'18"-1:13'59" & 4'41" \\
\hline 1:13'59"-1:15'57" & 2'38" & 1:15'57"-1:19'03" & 3'46" \\
\hline 1:19'03"-1:21’08” & 2’05” & 1:21’08"-1:21’33" & 0’25" \\
\hline 1:21'33"-1:26'30" & 5'37" & 1:26'30"-1:28'35" & 2'05" \\
\hline 1:28'35"-1:32'10" & 4'15” & 1:32'10"-1:40’45" & 8'35" \\
\hline 1:40’45”-1:45’03” & 4'58” & 1:45’03"-1:49'22" & 4'19" \\
\hline 1:49'22"-1:52'59" & 3’37" & 1:52'59"-1:53’39" & 1'20' \\
\hline 1:53'39"-1:59'30" & 6’31" & & \\
\hline TOTAL & 79'15” (60,8\%) & TOTAL & $51^{\prime} 65 "(39,2 \%)$ \\
\hline
\end{tabular}

Fuente: Elaboración propia

Viendo los datos expuestos en el Cuadro 5 podemos concluir que en la película La guerra de las galaxias hay notablemente más minutos de música presente que de música ausente. El 60,8\% de la película está acompañada de la banda sonora.

No obstante, si observamos dónde hay más tiempo continuado de música presente o música ausente, observamos que hay más tiempo continuado de música ausente (8'35”) en las escenas: "Nos dejan ir", "La llegada a Yavin 4", "Reunión rebelde”, "Partida de Han y Luke” y "Biggs". Estas escenas son de gran importancia pues se encuentran en la antesala del enfrentamiento definitivo entre el bien (Luke) y el mal (Vader). Por otro lado, en cuanto a la música presente, hay música de manera continuada desde que empieza la película hasta el minuto 8'17" en las siguientes escenas: “Una nueva esperanza”, "Partida imperial de abordaje", "La misión de Artoo" y "Vader se enfrenta a la princesa”. Estos 8 minutos continuados de música son una declaración de intenciones de lo que va a ver y escuchar el espectador durante toda la película. Es importante observar el Cuadro 1 y el Cuadro 5 para ver que nos encontramos ante una de las partes con más tiempo de música continuado.

Ante estos datos, observamos que la carga narrativa que aporta la música es clave para la película tanto en la sincronización con las acciones como en el dramatismo añadido en los contenidos acompañados de banda sonora (60,8\%).

\subsection{La clasificación de la música utilizada}

La música que aparece en este film mayoritariamente puede catalogarse como música extradiegética según la terminología de Cueto (1996), es decir, aquella que aparece de fondo mientras se está desarrollando la escena, sin ninguna otra intención que la de reforzar esa acción que está transcurriendo en ese momento. 
Sólo en dos escenas podemos hablar de música diegética. La primera, cuando llegan Ben, Luke y los androides (C3-PO y R2-D2) a la estación espacial de Mos Eisley en busca de un piloto (Han Solo que será interpretado por Harrison Ford). Para contratar a un piloto entran en la cantina de la estación y nada más llegar se escucha el murmullo de los personajes que se encuentran en la escena y una música de fondo. La música que suena es al estilo de jazz swin (esta escena está inspirada en el saloon del oeste). Este estilo de música no ha aparecido antes en la película y fue compuesta originalmente para la misma. En un principio, no se muestra la fuente de la que procede la música pero unos segundos más tarde sí, por lo que podemos hablar de un sonido acusmático que se convierte en un sonido diegético in visualizado. La segunda vez que aparece la escena en la cantina, cuando suena la música, nos presentan la fuente de la que proviene la música desde el primer instante, con planos de los personajes que están tocando los instrumentos. Se trata de una banda que está amenizando la cantina y que tocan en directo durante el desarrollo de la escena. Tras observar esta escena podemos decir que se trata de sonido in diegético visualizado, es decir, la fuente (en este caso los componentes de la banda) aparece en la imagen y pertenece a la realidad que ella evoca. Se presenta con planos de los músicos tocando sus instrumentos y una vez que el espectador tiene consciencia de ello, pueden realizar un cambio de escena con total naturalidad, ya que el espectador conoce cuál es la procedencia de la música que se está escuchando. Este tipo de música es el más realista que existe, ya que la imagen y el sonido están totalmente vinculados. Debemos aclarar que tanto la música presente/ausente diegética como la música extradiegética han sido compuestas originalmente para este film por John Williams.

Por tanto, a pesar de encontrarnos mayoritariamente con música extradiegética, ésta adquiere un valor trascendental e importante en la narración audiovisual y no es ajena a lo que está sucediendo.

Ante la exposición de los resultados y la discusión de los mismos, el artículo cumple el objetivo inicial con el que pretendemos demostrar que la banda sonora y, en definitiva, el uso de la música puede otorgar un valor añadido notable a la obra audiovisual.

\section{Conclusiones}

La carga narrativa de La guerra de las galaxias recae en gran medida en la música como hemos observado en la ejecución de los leitmotiv del film. En este sentido, el uso de determinados instrumentos conlleva connotaciones relacionadas con el físico o la personalidad de los protagonistas. De hecho, hemos visto que la película perdería un importante sentido narrativo sin la música (el 60,8\% de la película tiene música presente como hemos visto en el Cuadro 3) ya que acompaña las acciones, les aporta dramatismo, las contextualiza e incluso adapta los instrumentos a las características físicas de los personajes con el empleo magistral de los leitmotiv. Es más, los instrumentos pasan a convertirse en marcadores de la acción generando efectos sonoros gracias a la sincronización (véase el Cuadro 4). Por tanto, la composición de la música aporta no sólo valor añadido a la obra cinematográfica, sino también sentido a la narración audiovisual. 
El análisis cuantitativo refleja que La guerra de las galaxias impulsó y dio importancia al papel de los compositores en la creación de las películas. El film resaltó la importancia de la banda sonora e impulsó la consolidación de la neosinfonía como forma narrativa para contar historias. La obra gira en torno a cuatro leitmotiv principales que no solo no cansan al espectador sino que, combinados (Cuadro 3), enriquecen la visualización de la película.

Por tanto, la ficción requiere de un apoyo musical magistral no solo para ser verosímil sino para dar carga narrativa a la obra. En este sentido coincidimos con González (2006: 76) cuando concluye que Williams inventó música para "un mundo nunca visto y para acompañar a unos personajes épicos y a sus oscuros contrapuntos".

Por último, la música adquiere tal importancia en la creación de la obra audiovisual que se ha convertido en una nueva unidad de negocio: la venta de la música creada y diseñada para una película determinada. George Lucas demuestra ser un apasionado por el sonido y por la música. Un visionario del cine que inicia su andadura cinematográfica con otro visionario de la música, Jonh Williams, que se inspira en el sinfonismo. Por tanto, el compositor adquiere un valor importante como coautor y constructor del sentido final de la obra.

\section{Referencias bibliográficas}

Adorno, T. W. y Eisler, H. (1981): El cine y la música. Segunda edición. Madrid: Editorial Fundamentos.

Alcalde de la Isla, J. (2007): "Pautas para el estudio de los orígenes de la música cinematográfica”, Área Abierta, 16, marzo 2007, p. 1 - 9. Disponible en: http://revistas.ucm.es/index.php/ARAB/article/viewFile/ARAB0707130006A/4160 [Consultada el 12/03/2012].

Bookbinder, R. (1982): Las películas de los años 70. Barcelona: Paidós Ibérica.

Carrero, A., Cervantes, V., Maglia, H., y Planas, J. (2001): Diccionario Gran Historia de la Música. Barcelona: Salvat Editores. Chion, M. (1996): El cine y sus oficios. Madrid: Ediciones Cátedra.

Chion, M. (1997): La música en el cine. Barcelona: Paidós Ibérica.

Colón, C. (1993): Introducción a la historia de la música en el cine. La imagen visitada por la música. Sevilla: Ediciones Alfar.

Colón, C., Infante del Rosal, F. y Lombardo, M. (1997): Historia y Teoría de la Música en el Cine. Presencias afectivas. Sevilla: Alfar.

Cueto, R. (1996): Cien bandas sonoras en la historia del cine. Madrid: Nuer Ediciones.

García, E. y Sánchez, S. (1997): Guía histórica del cine. 1895-1996. Barcelona: Film Ideal.

González Laiz, Gonzalo (2006): Guía para ver y analizar La guerra de las galaxias: George Lucas (1977). Barcelona: Octaedro.

96 | n 17, pp. 79-97| doxa.comunicación 
Hernández, M. y Grandío, Ma del M. (2011): “Narrativa crossmedia en el discurso televisivo de Ciencia Ficción. Estudio de Battlestar Galactica (2003-2010)”, Área Abierta, 28, pp. 1 - 20. Disponible en: http://revistas.ucm.es/index.php/ARAB/article/viewFile/ARAB1111130004A/4031 [Consultada el 03/03/2012].

López Hernández, Á. (2003): “El análisis cronológico-secuencial del documento fílmico”, Documentación de las ciencias de la comunicación, no 26, pp. 261-294. Disponible en: http://dialnet.unirioja.es/servlet/articulo?codigo=963389 [Consultada el 15/05/2012].

Lucas, G. (2004): Star Wars IV. La guerra de las galaxias. Una nueva esperanza [disponible en formato DVD]. USA: Twentieth Century Fox.

Marschall, G. (1996): "La ópera romántica”, en Beltrando-Patier, M. C. (ed.): Historia de la música. La música occidental desde la Edad media hasta nuestros días. Madrid: Espasa Calpe, pp. 577-655.

Mérida de San Román, P. (2002): El cine: historia del cine, técnicas y procesos. Barcelona: Larousse.

Montoya Rubio, J. C. (2010): Música y medios audiovisuales: planteamientos didácticos en el marco de la educación musical. Salamanca: Ediciones Universidad Salamanca.

Olarte, M. (2002): “La música incidental en el cine y el teatro”, en Banús, E.: El legado musical del siglo XX. Pamplona: Eunsa, pp. 151-179. Disponible en: http://gredos.usal.es/jspui/bitstream/10366/76674/1/DDEMPC_Olarte_Martinez_M_Lamusicaincidentalenelcine.pdf [Consultada el 12/05/2012].

Padrol, J. (2001): “La música en el cine”, en Carrero, A., Cervantes, V. y Ramírez, M. (coords.): Gran Historia de la Música. Barcelona: Salvat Editores.

Prado, A. (2011): "Europa frente a Hollywood: breve síntesis histórica de una batalla económica y cultural”, Doxa Comunicación, $\mathrm{n}^{\circ}$ 12, pp. 39-59. Disponible en: http://www.doxacomunicacion.es/pdf/europafrenteahollywood.pdf [Consultada el 18/05/2012].

Williams, J. (2004): “Banda sonora Star Wars", en Lucas, G.: Star Wars IV. La guerra de las galaxias [disponible en formato DVD]. USA: Twentieth Century Fox. 